\title{
SOBRE O MODELO FAMILIAR DE IÊ E SEU DEVIR NA CONTEMPORANEIDADE: DESLOCAMENTOS E RESILIÊNCIA
}

Martín Fabreau Martinez ${ }^{1}$

Resumo: Em este texto me proponho traçar um panorama plausível sobre a noção de $i \hat{e}$, vinculado a um modelo de organização familiar tradicional assim como também à ideia de 'casa', no Japão moderno e seu devir no contexto da imigração para o Brasil nos começos e meados do SXX e posteriormente no contexto já das dinâmicas transnacionais vinculadas à globalização. Posteriormente, a partir de dois correlatos empíricos de nikkeis que atualmente moram em Pernambuco e também na Bahia tentarei explorar como esse projeto de iê ainda tem lugar numa contemporaneidade signada pela crescente mobilidade, e ainda mais, como nesses casos concretos o conceito é ressignificado como a consecução de um projeto social baseado principalmente em relações de parentesco englobando a vários integrantes do grupo familiar comportando diversas estratégias tendentes a organizar e garantir a sua perpetuação; Palavras-chave: Iê; Dinâmicas Geracionais; Presença nikkei no Vale do São Francisco; Cooperativa Agrícola de Cotia; Mobilidade Espacial;

Abstract: My objective here is to expound a plausible outlook of the notion of $i e$, associated to a model of traditional family organization as well as to a idea of 'house', in the modern Japan and its come about in the context of the immigration to Brazil at the beginning of the $20^{\text {th }}$ century, and afterwards in the context of de transnational dynamics linked to globalization. Then, from some empirical cases of nikkeis who actually live in Pernambuco and Bahia, I'll explore how this ie project is still operative at this contemporaneity marked by an increasing mobility, and also how, in those specific cases, this concept is resignificated as the consecution of a social project mainly based on kinship relationships including several members of the family group involving several strategies tending to organize and guarantee its perpetuation;

Keywords: Ie; Generational Dynamics; Nikkeis at the Vale do São Francisco; Cooperativa Agrícola de Cotia; Spatial Mobility.

1 Doutor pelo Programa de Pós-Graduação em Antropologia da Universidade Federal de Pernambuco (PPGA - UFPE); Docente da Área de Estudios Turísticos - Facultad de Humanidades y Ciencias de la Educación - Universidad de la República, Uruguay (AET - FHUCE - UDELAR); fabreau@gmail.com 


\section{Apresentação}

Muito se associa o conceito de iê à organização da família japonesa, seja no Japão, seja num contexto de imigração. Embora de uma polissemia e complexidade considerável, basicamente esse conceito remete à ideia de "casa" e ao mesmo tempo de "família" em tanto que projeto social organizado sob uma estrutura hierárquica patriarcal onde o pai detém o poder absoluto sobre o grupo e o primogênito varão será o herdeiro. Canonicamente a noção de iê tem se manifestado sob a forma de um modelo familiar tradicional baseado na produção agrícola.

Porém, dependendo de como seja entendido, poderá se assumir que o conceito de Iê tem sido ressignificado, produto das profundas mudanças sociais e culturais do Japão de pós-guerra, das mudanças nas relações de produção e os fenômenos de urbanização e ainda mais das diversas dinâmicas transnacionais signadas pela mobilidade; isso atinge também aos rumos que a iê tomou nos diferentes destinos de imigração.

Assim, é possível entrever que a pesar da eventual posta em xeque desse conceito, ele ainda veicula valores nuclearizantes do grupo familiar.

Em este texto me proponho traçar um panorama plausível sobre a noção de $i \hat{e}$ no Japão moderno e seu devir no contexto da imigração para o Brasil dos começos e meados do SXX e logo no contexto já das dinâmicas transnacionais vinculadas à globalização. Posteriormente, a partir de um correlato empírico baseado em trajetórias vitais de nikkeis que atualmente moram em Pernambuco e na Bahia tentarei explorar como esse projeto de iê tem lugar numa contemporaneidade signada pela crescente mobilidade, e ainda mais, como nesses casos concretos o conceito é ressignificado como a consecução de um projeto social em tanto que "jogo sério" (ORTNER, 2007) baseado principalmente em relações de parentesco que engloba a vários integrantes do grupo familiar e que comporta diversas estratégias tendentes a organizar e garantir a sua perpetuação.

\section{Sobre o forjamento de Î no nascente Japão Moderno: um correlato de "Tradição Inventada"}

O presente texto gira em torno a um objeto problemático e complexo por suas múltiplas dimensões; ainda mais, um objeto que as diversas modificações que tem sofrido nessas dimensões deveio ainda mais complexo em tanto que figura conceitual, e até instável em tanto categoria analítica. Em definitiva iê é ao mesmo tempo uma instituição social, uma figura jurídica (embora vaga), mas também um conceito.

Não me proponho aqui traçar de maneira detalhada tudo o que a figura de $i \hat{e}$ comporta, mas apenas estabelecer um panorama plausível para logo achar um correlato na contemporaneidade.

A pergunta que quiçá motive este exercício seja sobre a pertinência de rastrear na atualidade as traças de uma instituição que remete simultaneamente a uma modalidade de organização familiar patriarcal própria do feudalismo (Era Edo 1600-1867), a uma 
figura jurídica forjada na Era Meiji (1868-1912) e logo abolida após a Segunda Guerra, e a um conceito vago e difuso porém presente até o dia de hoje.

Assume-se que o surgimento do Japão Moderno tem lugar quando a Restauração Meiji (1866-1869) põe fim aos mais de 250 anos do Shogunato Tokugawa marcando assim o final do sistema feudal no Japão e o começo da sua apertura ao Ocidente instaurando um modelo de Estado Moderno e um Código Civil altamente influenciados pelos critérios europeus da época mantendo porém a figura do Imperador, emblema vivente e símbolo de união merecedor de honra e lealdade.

É neste contexto que $i \hat{e}$ em tanto que figura jurídica da organização básica familiar baseada na organização da Classe Samurai se inscreve no Código Civil Meiji estendendo-se assim para o resto da sociedade uma forma organizativa familiar que na Era Edo era exclusiva de um grupo reduzido e privilegiado.

Com a derrota do Japão em 1945 e a ocupação do seu território por parte dos EUA, a sociedade japonesa sofrerá profundas modificações entre elas a abolição do Código Civil da era Meiji e a instauração de um novo Código em 1947.

Resulta evidente que os processos históricos não acontecem por decreto, assim como também, as marcas da tradição continuam permanecendo as mais das vezes, cristalizadas em valores; de fato até o dia de hoje emerge o conceito de iê em alguns contextos.

Voltando ao nascente Estado japonês, a apertura para o Ocidente e a conseguinte geração de um Estado Moderno e centralizado, consequência da restauração Meiji, geraram importantes mudanças no que tem a ver com as formas de organização política e produtiva do Japão. Entre elas pode-se destacar a abolição do feudalismo e como uma das várias consequências disso, a regulação sobre propriedade privada da terra. Assim, o Direito acabou virando um importante instrumento político (VILLASEÑOR, 2011; AWAIHARA, 2000).

Como já o assinalou Stuart Hall (2001), uma cultura nacional se compõe de instituições mas também de discursos; assim a narrativa da cultura nacional comportará uma série de estratégias discursivas que operarão como fonte de significados: uma narrativa da Nação que proporcione histórias, símbolos, rituais, territórios, etc., um ênfase nos origens, na continuidade, na tradição e na atemporalidade gerando assim uma 'essência' desse povo, uma invenção da tradição onde se criem práticas e representações que pareçam ser de longa data embora sejam recentes, um mito fundante que marque um caráter nacional e a ideia de um povo puro e original com origens ancestrais. Desta maneira, o discurso da cultura nacional constrói identidades que são colocadas entre o passado e o futuro de uma maneira ambivalente (HALL, 2001).

Desta maneira, o nascente estado moderno japonês lançou mão de um certo discurso produtor de uma tradição comum porém inventada no sentido de Hobsbawm (HOBSBAWM, 2002; VILLASEÑOR, 2011). Assim se criará um povo homogêneo com raízes comuns que vêm desde tempos imemoriais, e tudo isso logo se fixará em um código. Dentre as várias 'ficções' forjadas na Era Meiji está a construção de uma (única) 'família tradicional japonesa' (VILLASEÑOR, 2011). 
Esse modelo de família tradicional escolhido para virar 'tradição' era apenas um dos vários modelos existentes segundo as regiões e as posições sociais. Concretamente o patrão de família utilizado na restauração Meiji foi um baseado na patrilinearidade com um sistema de primogênito herdeiro. Desta maneira se abole o sistema de castas e se estende para toda a sociedade o modelo de organização familiar da Classe Samurai². Assim, a figura da $i \hat{e}$ foi em certa medida 're-criada' para servir os interesses no nascente estado moderno Japonês.

Observe-se esse paradoxo de apelar à tradição e a valores tradicionais para servir melhor ao estado, integrando a família à nação (AWAIHARA, 2000). Na verdade ocorre que a família é integrada numa estrutura social altamente hierarquizada com o Imperador acima de tudo (de fato, nisso se tratou a restauração ${ }^{3}$ ). Desta maneira, baseando-se numa moral confucianista que descansa na 'piedade filial', no interior do grupo doméstico a subordinação é para o chefe a iê e para fora do grupo doméstico é para com a figura paternal do Imperador, máxima emblema da grande família do Estado (VILLASEÑOR, 2011; AWAIHARA, 2000).

Por último, vale fazer a seguinte pontualização. As referências a iê no código civil Meiji promulgado em 1898 não eram claras nem específicas senão que iê cobrava forma quando era declarada pelo chefe no registro de famílias promulgado a partir de 1871 que em definitiva tinha como finalidade a fiscalização e o controle social e fiscal por parte do Estado e em última instância a geração de um registro a ser utilizado com miras ao alistamento militar. Isto resulta relevante para os especialistas em Direito pois tira o 'status' de figura jurídica de $i e$, virando antes que nada, uma petição de principio propícia e concordante com a tese da tradição inventada (VILLASEÑOR, 2011).

Ya dejé claro que para poder analizarla ie no podemos recurrir a una definición legal; sin embargo, lo más próximo a un intento por regular la "creación" de la ie fue el registro familiar (koseki). Este contenía la información más importante referente al estatus social de los miembros de la ie. Se preparó para varias prefecturas, después de la Renovación Meiji, y, a diferencia de los registros anteriores, servía tanto para la nobleza como para los antiguos samurái y los campesinos. (...)

La ie se "creaba" cuando el jefe de la familia daba el aviso correspondiente y se asentaba en el koseki. El registro, en este sentido, más que reconocer "creaba" la ie, así que el concepto seguía vacío y era únicamente un continente con un contenido variable. No habiendo un artículo que definiera la ie, ésta cobraría existencia cuando la registrara el jefe. (VILLASEÑOR, 2011, pp. 121-122)

2 É por isso que alguns autores o denominam "processo de samuraização" (WOORTMANN, 1995).

3 "El grito de guerra que anunció en el Japón la era moderna fue Sonnojoi, 'Restauremos al emperador y expulsemos a los bárbaros'. Era una consigna que intentaba mantener al Japón incontaminado del mundo exterior y restaurar la edad de oro del siglo $\mathrm{X}$, antes de que existiera el «poder dual» del Emperador y el Shogun.” (BENEDICT, 2006, p. 61) 


\section{A Iê em tanto modelo de organização familiar}

Nas linhas precedentes tentei mostrar a complexidade que subjaz por trás de este conceito. No entanto, e seja como for, para os presentes fins é necessário pelo menos delinear algo assim como um 'tipo ideal' do iê em tanto que forma de organização familiar para tentar esclarecer de que se fala quando se alude a essa instituição e assim começar a trabalhar também a partir de 'positividades'.

La ie, tradicionalmente, fue la forma de ordenación social de la familia, contenía roles dados para el jefe de familia, los sucesores, los hijos e incluso los difuntos. Los distintos roles y generaciones de la ie estaban caracterizados por principios confucianos de lealtad y benevolencia y las generaciones más jóvenes veían su deber hacia la ie como lealtad hacia sus padres por la benevolencia recibida. (Joy Hendry apud VILLASEÑOR, 2011, p. 97).

Como estabelecido, iê é um grupo familiar de descendência patrilinear e está fortemente associado a uma modalidade de produção agrícola e em grande medida gira em torno à regulação da propriedade da terra e dos médios de produção. A residência é patrivirilocal mas a adoção do genro é uma prática aceita se contribuir à continuidade de iê (TABLERO, 1992). O grupo está completamente subordinado à autoridade do pai quem é o chefe de $i e ̂$ e como já foi dito os valores morais que regulam a hierarquia e seu funcionamento são próprios do confucionismo. A herança do total da propriedade lhe corresponde ao primeiro filho varão quem permanecerá na casa toda sua vida tomando conta da produção e se for o caso tomando conta dos pais idosos, enquanto os filhos restantes não herdarão e geralmente abandonam a casa para formar suas próprias $i \hat{e}$. Só para dar uma ênfase pertinente, vale a pena remarcar e fazer explícito o fato de que em esta modalidade patriarcal as mulheres jamais tinham status de herdeiras.

Sobre o lugar desse(s) filho(s) não herdeiro(s), Francisco Tablero estabelece que

Contrariamente al primero su destino será abandonar la ie bien a través del matrimonio-adopción en otra ie sin heredero o bien trasladándose a la ciudad o bien constituyendo la suya propia e independiente en la misma comunidad. En este último caso los lazos con su ie natal no son rotos definitivamente. (TABLERO, 1992, p. 112).

Quando se estudam processos migratórios, é interessante olhar para a figura do filho não herdeiro do grupo familiar, pois geralmente são eles que tomam a iniciativa de emigrar na procura de uma forma rápida de gerar um Capital inicial.

Estruturalmente a figura de iê atribui e regula hierarquicamente o lugar para os vários integrantes do grupo familiar (pais, filhos, irmãos, tios, sobrinhos, avôs, etc.). 
Além do mais, iê regula também o lugar dos defuntos no grupo familiar e até no âmbito doméstico mediante o regular culto aos antepassados. Desta maneira se está frente a uma forma de família extensa com várias gerações convivendo sob um mesmo teto seja presencialmente, seja na memória do grupo.

É bom lembrar, no entanto, que aqui está se trabalhando sobre um modelo ideal de iê e que nos casos concretos nem sempre as coisas tomam uma única forma; por exemplo, nem sempre em iê estão sendo ocupados todos os lugares estruturais de parentesco, e também habilita pensar o caso de que até um filho não herdeiro com sua esposa e filhos, poderiam chegar a ter seu lugar dentro do grupo sob a chefia do seu irmão maior.

Como bem assinala Tablero, a instituição de iê tem suscitado interesse por dois aspetos mutuamente vinculantes, por um lado em tanto grupo básico de co-residência onde têm lugar relações de parentesco e se desenvolvem diversas estratégias para garantir sua perpetuação, e por outro em tanto unidade produtiva cujo funcionamento comporta dimensões econômicas, políticas, simbólicas, etc. (TABLERO, 1992). Isso não faz mais do que continuar mostrando outros aspetos da complexidade da figura da iê; se nas seções anteriores tentei mostrar a complexidade em tanto objeto que apresenta uma historicidade, e em tanto figura jurídica ou pelo menos que apresenta uma regulação jurídica, agora fica também de manifesto a sua complexidade em tanto que instituição social, âmbito de variadas relações e funções. Essa complexidade tem um correlato etimológico, já que o termo iê é marcadamente polissêmico e difícil de traduzir univocamente, admitindo um duplo significado em tanto família ou grupo doméstico e em tanto casa ou lugar de co-residência.

Para encerrar esta parte, gostaria de acrescentar que, em tanto que unidade produtiva, a estrutura hierárquica de iê tem se mantido por ser funcional às condições econômicas e produtivas da vida local. Tablero (1992) faz menção ao fato de que a terra disponível e cultivável geralmente sempre tem sido escassa, daí que pareceria ser mais rentável deixar a totalidade da terra a um único sucessor (TABLERO, 1992), e pode se acrescentar que o elemento regulador de esta dinâmica é o cúmulo de obrigações e potestades veiculados na moral confucianista.

Desta maneira, até o final da Segunda Guerra Mundial era bastante comum ver três ou quatro gerações morando numa mesma casa sob a liderança de 'pai-chefe-da$i \hat{e}$ '. Porém a derrota do Japão e a conseguinte ocupação do território por parte dos EUA trouxeram outras novas e profundas mudanças 'ocidentalizantes' entre elas a abolição em 1947 do Código Civil Meiji e a instauração de um novo Código Civil. As repercussões que isso teve no plano da família foram a abolição (formal) do sistema de iê e sua substituição por um modelo predominante de família nuclear, é claro também que o forte processo industrial, urbanizador e o crescimento econômico dos anos '50 e '60 foram em grande medida decisivos para favorecer este novo tipos de arranjo familiar. $\mathrm{Na}$ produção rural, uma consequência direta de esta concatenação de mudanças foi a 
supressão do sistema do primogênito herdeiro, e em contrapartida, a sucessão em partes iguais para todos os filhos do grupo.

Mereceria um trabalho aparte a análise sobre as implicações que tais mudanças tiveram na vida social das mulheres ${ }^{4}$.

\section{Dinâmicas de Iê no contexto da migração japonesa ao Brasil}

A migração sistemática e planejada do Japão para o Brasil tem seu começo simbólico em abril de 1908 em que um navio com cerca de 780 imigrantes arribou ao porto de Santos. Com a chegada do KasatoMaru iniciou-se um profuso fluxo entre ambos países que iria trazer consequências pouco imaginadas para a conformação da Cultura Nacional brasileira e que até o dia de hoje, quase 110 anos depois, ainda continuam tendo cabida. Alcança ver as datas para compreender que aquelas dinâmicas de organização familiar que tiveram lugar no Japão na era Meiji e também logo, encontraram um correlato no contexto da imigração japonesa ao Brasil.

Como estabelece Ellen Woortmann (1995), embora fatores estruturais 'macro' possam determinar a migração, não são eles que a organizam; "essa organização da migração frequentemente se dá no âmbito de uma linguagem de parentesco que ré/ constrói e ultrapassa os limites das relações de parentesco em sentido mais estrito" (WOORTMANN, 1995, p. 2). Assim, todo um repertório de valores tradicionais incluindo obviamente valores familiares estaria operando na contemporaneidade compassando determinadas regularidades e dinâmicas na organização familiar no contexto da imigração. Desta maneira, aqui no Brasil em linhas gerais nas famílias nikkei se mantiveram (e até se mantêm) algumas das características próprias de $i \hat{e}$ tais como as relações de hierarquia e os valores relativos a essa modalidade patriarcal, o lugar especial do primogênito, a herança, a escolha da noiva pelo chefe de $i \hat{e}$, arranjo de casamentos, etc. Também neste contexto tiveram lugar dinâmicas familiares tais como matrimônios arranjados apenas para poder acessar aos planos de colonização (WOORTMANN, 1995).

Mas antes cabe salientar aqui o fato de que já no Japão a configuração de $i \hat{e}$ propiciou a emigração para outras partes como é o caso do Brasil, ao tempo que cabe lembrar que nesse mesmo tempo o governo japonês promovia importantes campanhas de emigração. Desta maneira aqueles filhos 'não herdeiros' se viram obrigados a procurar novos horizontes, tendo como objetivo fazer-se de médios para voltar e se instalar perto da casa familiar. Mas também na imigração japonesa ao Brasil havia primogênitos os quais achavam na vinda ao país uma forma rápida de capitalização para posteriormente retornar ao Japão ou enviar recursos desde aqui e assim continuar com a perpetuação do grupo familiar. O mito que regulou em grande medida a vinda ao Brasil durante o período prévio à Segunda Guerra foi "fazer a América".

4 Para uma detalhada abordagem, ver Muta (2006). 
É interessante a observação que faz Woortmann, mostrando que a pesar de que a emigração geralmente é percebida "como um fenômeno que diz respeito tão somente a expulsos estruturais, encobre o contingente daqueles que migram para manter a estrutura tradicional quando da sua volta." (WOORTMANN, 1995, p. 4).

Por razões de espaço não desenvolverei aqui todos os desdobramentos que o tema admite. A os efeitos deste trabalho baste sublinhar que no caso da imigração japonesa ao Brasil mais do que empreendimentos pessoais e isolados, o que está em funcionamento são projetos familiares em todos os sentidos que o termo abarca sustentados em fortes valores de grupo que alimentam forças nuclearizantes, e esses projetos têm a ver em grande medida com as dinâmicas que estabelece a $i \hat{e}$ e sua perpetuação.

É a estrutura de parentesco que serve de referência para esse deslocamento, constituindo-se em dupla solução: ao destinar alguns de seus filhos à migração, a «casa» viabiliza a reprodução social dos que ficam, assim como a hierarquia familiar; com a migração, o valor-família tradicional se estende a novos espaços, onde reorganiza a sua reprodução futura. (WOORTMANN, 1995, p. 8)

É importante lembrar à vez que salientar duas coisas. A primeira é que ao trabalhar sobre este tipo de processos históricos e culturais o risco de essencializalos e reifica-los está sempre presente (...ainda mais quando se trata de objetos 'orientalizáveis' e/ou exotizantes como a niponidade), daí que seja importante manter a vigilância sobre as possíveis interpretações que se possam fazer e não esquecer que em este plano desde donde se fala; em definitiva está-se trabalhando com 'situações ideais' que admitem vários correlatos empíricos. A segunda questão a lembrar e que está vinculada ao anterior, é que não se deve perder de vista que os processos históricos e culturais vinculados à imigração japonesa que tiveram lugar aqui no Brasil não foram meros reflexos do que podia acontecer no Japão senão que adotaram caminhos próprios e particulares. Assim, não se pode esquecer o fato das dinâmicas (conformadas por conflitos, posicionamentos, adscrições, ressignificações) que vão tendo lugar conforme se sucederam as gerações de nikkei. Em definitiva, não se deve esquecer esse leque de conflitos baseados entre a continuidade e a tradição e as mudanças.

Tendo chegado a este ponto, cabe começar a perguntar-se então que de tudo isso relativo a iê permanece a pesar das mudanças (no Japão e no Brasil). Embora que uma resposta satisfatória mereça um tratamento bastante mais detalhado, vale a pena pelo menos assinalar que a pesar de terem-se perdido hábitos e práticas concretas, há valores relativos à família tradicional e ressignificações relativas a $i \hat{e}$ que continuam pautando formas de pensar, agir e atuar. Ou em palavras de Woortmann, "perderam-se hábitos mas não o "habitus"; o "valor família" continua orientando o grupo." (WOORTMANN, 1995, p. 14). 


\section{O fenômeno dekassegui e a construção da família transnacional Nikkei}

Se cem anos atrás o fluxo de imigrantes era no sentido Japão-Brasil, sem duvidas hoje dia tem-se invertido ou, aliás, mas do que japoneses chegarem ao Brasil, são principalmente brasileiros (ou issei) que vão para o Japão.

A principal modalidade de deslocamento e residência no Japão de grande relevância para a comunidade nikkei brasileira é o que se conhece como "fenômeno dekassegui", e está estreitamente vinculado com a globalização e às dinâmicas transnacionais associadas a ela. Em linhas gerais se trata do fluxo massivo de força de trabalho nikkei que a partir de meados da década dos '80 começa a se deslocar para o Japão com o cometido de trabalhar em fábricas e empresas em expansão altamente necessitadas de mão de obra e que realizavam uma oferta econômica importante por trabalhos que não necessariamente exigiam uma grande qualificação (KAWAMURA, 2003 e 2008; ROSINI 2004 e 2008).

Kawamura (2008) estabelece que no começo deste processo migratório a maioria dos imigrantes eram jovens que tinham uma expectativa de pronto regresso ao Brasil e com uma melhor situação econômica. Assim, Japão é pensado sob o signo da transitoriedade e em definitiva essa modalidade de residência torna-se 'residência em trânsito'; é por essa razão que nem sempre há uma previsão sobre o futuro ao longo prazo. Quase vinte e cinco anos depois gera preocupação o fato de ter uma população de imigrantes com uma importante proporção de pessoas com idades superiores aos cinquenta e muitos deles sem cobertura de benefícios por parte do Estado. Obviamente esta população é das mais vulneráveis no contexto da atual crise econômica.

Da mesma maneira que a vinda dos japoneses ao Brasil esteve organizada por essa 'linguagem de parentesco' mencionada acima e em definitiva em grande medida assentada nos valores e as dinâmicas da família tradicional, em este contexto de migração transnacional também operam dinâmicas familiares, seja estabelecendo o contexto sobre quem vai e quem permanece, seja gerando implicações fortes sobre essas famílias que começam a estabelecer conexões e relações de um país a outro possibilitando assim o estabelecimento de fluxos materiais e simbólicos de distinta ordem assim como também outras e variadas formas de relacionamento à distância que por sua parte geram quase que inusitadas modalidades de sentir os laços familiares. Estas características são de fato as que marcam a diferencia entre aquela migração dos começos e meados do SXX e esta modalidade deslocação que tem lugar neste contexto transnacional.

Se no caso de iê, quem herdava a propriedade era o primogênito, e só cabia aos não herdeiros se mudarem e iniciar um novo e próprio empreendimento (emigrar para o Brasil, ou aqui no Brasil mudar para outro local), em esta conjuntura de emigração transnacional em boa medida acontecem essas mesmas lógicas; os que saem serão os não herdeiros, no entanto como também já foi visto, também os herdeiros poderão sair se for o caso. 
Em larga medida, também cabe ainda ao primogênito um status hierarquicamente superior: realizar o casamento endogâmico, assegurar a continuidade do empreendimento familiar, cuidar dos pais idosos e permanecer no local. Para os demais filhos abre-se a possibilidade de assegurar seu futuro em outras áreas ou a opção por novos tipos de carreira profissional. Mas, há também primogênitos que vão para voltar e melhorar o patrimônio que irão herdar. A mesma migração e a categoria dekassegui envolvem orientações valorativas e projetos distintos.

(WOORTMANN, 1995, p. 14)

Como meu foco tem a ver com o peso da tradição e as práticas e significados que giram em torno a $i \hat{e}$, não vou aprofundar em todas as possibilidades de arranjos familiares, formas de vivenciar e manter o matrimônio e a filiação à distância, subjetivação do regresso etc., que acontecem em este tipo de dinâmica transnacional que de fato acabam indo bem mais além dessas questões. Baste dizer que em grande medida aqui também operam projetos de grupo e que a pesar da inexistência formal do sistema da família patriarcal tradicional sob a forma de $i \hat{e}$, como já foi dito, diversos valores tradicionais permaneceriam e ainda mais, permaneceria certo 'habitus' de família tradicional com tudo o que isso implica. Assim, poder-se-ia pensar que a pesar das mudanças próprias do devir histórico e das novas sínteses culturais que vão-se consolidando, algo desse ideal de família tradicional japonesa persiste e se cristaliza não somente em valores mas também em práticas e em estratégias e projetos em tanto que jogos sérios (ORTNER, 2007) que apontam à preservação do grupo doméstico.

\section{Nos Sertões: Iê, Dinâmicas Geracionais e Mobilidade no Contexto da Chegada de Nikkeis no Vale do São Francisco}

Para finalizar este trajeto conceitual, gostaria de apresentar um correlato empírico dos elementos desenvolvidos nas páginas precedentes.

$\mathrm{Na}$ minha pesquisa de Doutorado, na qual me dedico a estudar as diferentes estratégias associativas, produtivas, familiares e identitárias desenvolvidas no contexto da inserção e permanência de nikkeis procedentes principalmente das regiões Sudeste e Sul na agricultura irrigada do Pólo Petrolina-Juazeiro ${ }^{5}$, têm se evidenciado algumas dinâmicas de mobilidade assentadas na forma de organização sob um modelo de $i \hat{e}$ (FABREAU, 2016).

A comunidade nikkei no Vale do São Francisco (VSF) mais do que ser conformada por imigrantes agricultores vindos do Japão, ela é composta principalmente por nisseis, filhos de imigrantes chegados ao Brasil, na maioria dos casos, depois da Segunda Guerra Mundial. De maneira análoga ao que aconteceu com a expansão da produção de café

5 Em este contexto, opto por denominar indistintamente "Vale do São Francisco" (VSF) ou "Pólo Petrolina-Juazeiro". 
em São Paulo, ou da pimenta do reino na Amazônia, novamente se está diante de um processo de chegada de força de trabalho nikkei num contexto de fronteira agrícola.

A primeira chegada de nikkeis à região de maneira planejada teve lugar em 1983 através da Cooperativa Agrícola Cotia e mediante um convênio com a Codevasf ${ }^{6}$; vinte e nove famílias de jovens produtores, filhos de cooperados procedentes de São Paulo e Paraná, chegaram ao Lote 235 do denominado "Projeto Curaçá" (Município de Juazeiro - BA) com o objetivo de produzir principalmente uva mediante agricultura irrigada. Antes da chegada da CAC, já na década dos ' 70 havia algumas poucas famílias japonesas na região, vindas de maneira individual e não planejada. Em definitiva, poderse-ia estabelecer um primeiro momento, o dos pioneiros, e um segundo momento da chegada sistemática e relevante com a CAC como grande impulsor. Nesse sentido, pode se afirmar que a chegada da CAC ao Vale do São Francisco e tudo o que ela envolveu, marcará um momento importante na comunidade nikkei local, assim como também um ponto de inflexão na história produtiva do lugar.

Houve um terceiro momento na chegada de nikkeis à região sobre finais da década dos ' 80 e começo dos '90 no contexto da instauração do Projeto Nilo Coelho de agricultura irrigada, dessa vez do lado de Petrolina (PE). Na ocasião chegaram principalmente nisseis procedentes de todos os pontos de maior concentração nipobrasileira do Brasil (PR, SP, PA) os quais viraram grande produtores de uva e manga. Cabe mencionar que o Projeto Nilo Coelho não reúne apenas produtores nikkeis nem tampouco existem núcleos compostos apenas por eles. Fica claro que não houve um planejamento institucional direcionado para tal vinda senão que operaram principalmente redes étnicas, familiares e de sociabilidade.

Poder-se-ia reconhecer um quarto momento que vai desde meados da década dos '90 até o presente em que a presença nikkei mantém-se constante, após a queda da CAC a maioria dos ex-cooperados oranizaram-se fundando Cooperativa Agrícola de Juazeiro $(\mathrm{CAJ})$, e na década seguinte, surgiram algumas outras cooperativas menores também de alguma maneira influenciadas pela CAC, o agronegócio se consolida na região e já há uma segunda geração nascida no VSF.

Ao dia de hoje, a presença nikkei no VSF é heterogênea e apresenta uma importante estratificação social chegando ao entorno das 180 famílias; a comunidade não é composta apenas por fruticultores que moram em zonas rurais mas também por agrônomos, empresários, profissionais liberais em geral e produtores aposentados, fora algumas jovens e crianças. Alguns dos filhos desses nikkeis estudam fora, e muito poucos trabalham e moram no Japão. Praticamente na sua totalidade, esta comunidade está vinculada à agricultura irrigada.

Neste contexto de mobilidade interna, principalmente de filhos de imigrantes, cabe estabelecer que por trás da chegada da grande maioria dos nikkeis ao local há uma dinâmica geracional vinculada ao modelo de iê. Da mesma maneira em que o modelo de

6 Companhia de Desenvolvimento dos vales do São Francisco e Parnaíba. 
$i \hat{e}$ em grande medida deu a pauta sobre qual dos filhos permaneceria no lar paterno e qual deveria emigrar (para o Brasil no começos do SXX ou para Japão nos finais do SXX), também esta forma de organização fez com que geralmente os filhos não primogênitos saíssem do lar paterno em busca de outros horizontes para continuar seus projetos individuais/familiares. Conforme estabeleceu um agrônomo nikkei, ex técnico da CAC e atualmente vinculado à Codevasf, essa é a maneira em que predominantemente os japoneses vão se expandindo de região para região.

No caso da chegada ao VSF dos filhos de cooperados da CAC, foi a própria cooperativa que, unindo a necessidade de se expandir, ao mesmo tempo que de assegurar a perpetuação do seu projeto institucional, no critério adotado para a seleção dos jovens produtores foi visando dar lugar aos segundos filhos dos cooperados (ou filhos que não eram o primogênito); neste contexto é significativo inclusive o fato de um entrevistado mencionar que o termo utilizado na CAC era de "família Cotiana". Assim esse critério de expansão da CAC abrindo núcleos locais foi organizado segundo um critério que remete a um modelo familiar japonês. Por outro lado, ao mesmo tempo em que se contemplavam interesses institucionais, se resolvia um problema doméstico nas famílias dos cooperados.

Destarte os nikkeis do Lote 235 do projeto Curaçá se caracterizam por serem filhos de cooperados da CAC que ocupavam um lugar estrutural familiar diferente ao do primogênito.

Resumindo, por trás da chegada houve uma expansão espacial que implicou uma mobilidade espacial e um processo de re-territorialização baseado numa dinâmica geracional que remete à organização familiar tradicional de iê. No caso dos cooperados da CAC foi a própria cooperativa quem providenciou essa solução nos critérios de seleção ao tempo que garantindo para si própria a continuidade geracional e temporal. No caso do resto dos colonos no outros perímetros irrigados foi uma movimentação individual baseada em redes de sociabilidade e parentesco.

Se bem em todos os casos se reconhece que essa dinâmica geracional que pauta essa dinâmica espacial remete a uma modalidade familiar japonesa, poucos são os casos em que se fala explicitamente de ie.

\section{Palavras finais: Iê e 'resiliência'}

Conforme avança a problematização deste conceito na contemporaneidade, cada vez mais as perguntas sobre a sua viabilidade operativa ou do seu poder heurístico emergem e se multiplicam, mas por outro lado cabe a constatação de que as referências a $I \hat{e}$ se multiplicam traçando, organizando e/ou gerando uma modalidade (ainda que laxa) de organização familiar sob o signo da tradição patriarcal.

Será que essas forças nuclearizantes e projetos de grupo observados no contexto das famílias nikkei contemporâneas são apenas próprias de iê? Será que o conceito de $i e ̂$ virou uma camisa de força produto de uma vontade reificadora que está impedindo 
pensar e ver com clareza outras dinâmicas familiares além dela? São perguntas para levar a sério e continuar aprofundando; de momento o que há apenas são rascunhos.

Como linha argumentativa preliminar e a partir dos casos apresentados, gostaria assinalar por um lado que é possível perceber um certo caráter resiliente nesse conceito que de maneira geral continua de uma maneira ou de outra operando e formatando modalidades de agir, pensar e sentir, pautando desta maneira, certas 'marcas de tradição'. Por outro lado, corresponde ter a necessidade de conferir (ainda mais) um poder heurístico a esse conceito e explorar suas potencialidades se ele estiver articulando práticas e representações sob a forma de categoria nativa.

\section{Referências Bibliográficas}

AWAHIHARA, Y. “Japón: Familia em Transición”. X Congresso Internacional da Associação Latino-Americana de Estudos Africanos e Asiáticos. Cultura, Poder e Tecnologia: África e Ásia face à Globalização. Rio de Janeiro, 2000. Disponível em: <http://biblioteca. clacso.edu.ar/ar/libros/aladaa/>. Acesso em: 15 ago. 2017.

BENEDICT, R. El Crisantemo y la Espada. Patrones de la Cultura Japonesa. Madrid: Alianza Editorial, 2006.

FABREAU, M. Entre o Sakura e as Uvas. Transformações e Continuidades Familiares, Organizacionais e Identitárias entre os Nikkeis do Vale do São Francisco. Uma Etnografia Sobre Trajetórias na Agricultura Irrigada. Recife: Tese apresentada ao Programa de PósGraduação em Antropologia da Universidade Federal de Pernambuco, 2016.

HALL, S. A Identidade Cultural na Pós-Modernidade. DP\&A Editora, 2005.

HOBSBAWM, E. "Introducción: La invención de la tradición". In: HOBSBAWM, E. e RANGER, T. La Invención de la Tradición. Barcelona: Crítica, 2002. pp. 7-21.

KAWAMURA, L. Para Onde Vão os Brasileiros?. Campinas: Editora Unicamp, 2003.

KAWAMURA, L. "Brasileiros no Japão: Direitos e Cidadania". In: HASHIMOTO, F., TANNO, J. e OKAMOTO, M. Cem Anos Da Imigração Japonesa. História, memoria e arte. São Paulo: Editora Unesp, 2008. pp. 79-98.

MUTA, K. “Las Mujeres Japonesas en el Siglo XXY más allá”. In: MUTAKAZUE, SEUNGSOOK MOON, LI XIAOJIANG Y AMELIA SÁIZ LÓPEZ. Mujeres asiáticas: cambio social y modernidad. Barcelona: CIDOB ediciones, n. 12, pp. 15-36, 2006. Disponível em: $<$ http://www.cidob.org/es/publicaciones/documentos/asia/mujeres_asiaticas_cambio_ social_y_modernidad $>$. Acesso em: 15 ago. 2017.

ORTNER, S. B. "Poder e projeto: reflexões sobre agência". In: GROSSI, M. P.; ECKERT, C.; FRY, P. H. (orgs.). Conferências e diálogos: saberes e práticas antropológicas. $25^{\mathrm{a}}$ Reunião Brasileira da Antropologia - Goiânia. Blumenau: Nova Letra, 2007. pp. 45-80.

ROSINI, E. A nova diáspora: migrantes Nikkeis do Brasil para o Japão. Trabalho apresentado no VIII Congresso Luso-Afro-Brasileiro de ciências Sociais. 2004. Disponível em: <www. ces.uc.pt/lab2004/pdfs/RosaRossini.pdf >. Acesso em: 15 ago. 2017. 
ROSINI, E. O sonho de voltar rápido do Japão para viver no Brasil agora é uma utopia: os Nikkeis do Brasil no Japão. Trabalho proposto para apresentação no VI Encontro Nacional de Estudos Populacionais - ABEP. 2008. Disponível em: <www.abep.nepo. unicamp.br/encontro2008/docspdf/ABEP2008_1246.pdf>. Acesso em: 15 ago. 2017.

VILLASEÑOR, F. "Derecho y discurso en la creación del modelo de familia japonés IE". Estudios de Asia y África, México, v. 46 n. 1, pp. 97-126, jan./abr., 2011. Disponível em: <http://codex.colmex.mx:8991/exlibris/aleph/a18_1/apache media/6LL6HAF2LX3MMY62Q6MGEU341U69C1.pdf .

TABLERO, F. Parentesco y Organización del Sumo en Japón. Tesis de Doctorado. Universidad Complutense. Facultad de Filosofía y Ciencias de la Educación. 1992. Disponível em: $<$ http://eprints.ucm.es/2297/>. Acesso em: 15 ago. 2017.

WOORTMANN, E. Japoneses no Brasil/Brasileiros no Japão: tradição e modernidade. Série Antropologia - 183. UNB, Brasil. 1995. <http://dan.unb.br/images/doc/Serie183empdf. pdf>. Acesso em: 15 ago. 2017. 